\title{
MODELO PARA CUSTOMIZAÇÃO EM MASSA NA IMPLEMENTAÇÃO DE MICRO E PEQUENOS EMPREENDIMENTOS
}

Eduardo Rocha Garcia (erg.engst@gmail.com) - Escola de Engenharia, Universidade Federal do Rio Grande do Sul

Ângela de Moura Ferreira Danilevicz (angelamfd@producao.ufrgs.br) - Escola de Engenharia, Universidade Federal do Rio Grande do Sul

\begin{abstract}
RESUMO
Os micro e pequenos empreendimentos (MPEs) são a mola propulsora da economia. Contudo, vivenciam uma escassez de sistemas e métodos que permitam realizar seu gerenciamento e responder com flexibilidade e rapidez às mudanças do mercado, como a Customização em Massa (CM). $O$ artigo objetiva propor um modelo adaptado de CM para MPEs tendo foco na estratégia de diferenciação. O cenário selecionado para o estudo piloto foi o planejamento e implantação de uma microempresa de alimentos congelados saudáveis, buscando personalizar o pacote produto-serviço sem afetar tempos e custos de produção - cerne da CM. Para adaptar o modelo de CM, baseou-se em uma aplicação da literatura, modificando-se o necessário para viabilizar sua utilização para MPEs, tendo suporte de ferramentas: Business Canvas, Matriz SWOT e Gestão de Requisitos. O modelo adaptado possui seis etapas, alocadas em quatro estágios preconizados pela CM, e dois fluxos de melhoria contínua (kaizen). Verificou-se o atendimento customizado de $85 \%$ dos requisitos dos clientes e também um novo tipo de cliente, ampliando as fontes de receita com o mesmo produto. $O$ modelo adaptado conferiu diferenciação estratégica ao negócio foco da pesquisa e, guardadas as particularidades de cada segmento, pode ser utilizado para auxiliar na agregação de valor a startups.
\end{abstract}

Palavras-chave: customização em massa, micro e pequenas empresas (PMEs), empreendedorismo, alimentos congelados saudáveis, estratégia de diferenciação.

Área: Modelos de processo para o desenvolvimento de produtos e serviços.

\section{INTRODUÇÃO}

O cenário contemporâneo do mercado de trabalho, modificado pelo mundo globalizado, vem alterando as características dos domicílios. As pessoas estão dedicando maior tempo às atividades laborais, o que acaba por impactar diretamente na sua quantidade de tempo livre, tornando a opção pela terceirização de certas atividades extra profissionais uma realidade (ALBORNOZ, 2010).

Igualmente, vêm ocorrendo alterações no comportamento do consumidor, o qual tem se tornado mais exigente em termos das características e da qualidade do produto, bem como em relação à qualidade do serviço de atendimento (FREITAS, 2005). Atualmente, esta é considerada elemento-chave da satisfação do cliente, sendo o agente capaz de promover melhores resultados financeiros para a empresa (SHARABI, 2014).

Este cenário motiva alterações tanto nos produtos quanto na forma de gestão. Tachizawa et al. (2006) salientam a necessária modificação do papel dos gestores nas atividades do negócio como forma de atender às exigências de qualidade e de competitividade. Paralelamente, o desenvolvimento de produtos deve contemplar uma maior agregação de valor, desdobrada 
tanto em requisitos esperados quanto em não esperados. O primeiro pode ser traduzido pelas expectativas do cliente, ao passo que o segundo pode ser considerado como o conjunto de características inovadoras e atrativas ao consumidor. Em complemento, a qualidade dos serviços também influencia a valorização do produto, já que o consumidor, quando o adquire, acaba por receber benefícios intangíveis associados ao pacote produto-serviço (FITZSIMMONS; FITZSIMMONS, 2014).

Neste contexto, a palavra 'conveniência' ganha proporções significativas na rotina das pessoas. Consolidam-se, assim, novos produtos e serviços, aliados ao desenvolvimento da Internet, como e-commerce e tele-entregas de produtos, como a de comidas congeladas (RAMOS; COSTA, 2000). Adicionalmente, cresce o conjunto de demandas associadas à valorização de refeições saudáveis (SICHIERI, 2013).

Frente ao cenário de valorização de conveniência e de qualidade de vida, identificou-se a oportunidade de exploração de novos negócios como forma de atender a demandas de grandes centros urbanos. Para tal, o presente artigo tem por objetivo o planejamento e a implantação de Modelo de Negócio diferenciado no segmento de alimentos congelados saudáveis. Quanto aos resultados, espera-se desenvolver uma fatia de mercado que permita a operacionalização e a sustentabilidade do empreendimento.

O presente artigo é estruturado em cinco seções, sendo que a primeira contém o problema de pesquisa. Na seção dois, apresenta-se o referencial teórico necessário para embasar o desenvolvimento do trabalho, incluindo estratégia de diferenciação e customização em massa. $\mathrm{Na}$ terceira seção, é descrito o método de trabalho. Na quarta seção, são apresentados e discutidos os resultados oriundos do planejamento e da implementação do negócio, para na quinta e última seção serem descritas as considerações finais e as sugestões de trabalhos futuros.

\section{ESTRATÉGIA DE DIFERENCIAÇÃO E CUSTOMIZAÇÃO EM MASSA}

A estratégia de diferenciação é uma das grandes estratégias competitivas. Esta se destaca por haver um produto, um serviço ou um modelo de negócio ofertado de uma maneira distinta dos demais existentes no mercado, conferindo uma vantagem competitiva à empresa. Para sua manutenção, faz-se necessário um acompanhamento constante da movimentação da concorrência e, sempre que necessário, realizar alterações na formatação da estratégia (PORTER, 1996).

Empreender com foco em diferenciação exige, além de planejamento, insights mercadológicos como forma de potencializar o sucesso desse negócio. A utilização de ferramentas que permitam o delineamento do Modelo de Negócio pode contribuir para a otimização do processo de tomada de decisão (MÜLLER, 2003). Dentre estas ferramentas, está a desenvolvida por Osterwalder e Pigneur (2011) - Business Model Canvas. Esta ferramenta permite entender quais são os potenciais segmentos do cliente, que valor o produto e/ou serviço tem para estes clientes, como será entregue este valor, que tipo de relacionamento será operacionalizado, que atividades serão realizadas, que parcerias deverão ser estabelecidas, que recursos serão necessários, quanto custará este produto/serviço e quais serão as fontes de receita. Assim, é estabelecido o modus operandi de fornecimento de um produto e/ou serviço de valor para o usuário.

Dentre as possíveis estratégias competitivas de Porter (1996) para a inserção de uma empresa no mercado, a de diferenciação é aquela que visa acrescentar novos sistemas e formas de ofertar produtos e serviços em um negócio, tornando-o único. Como forma de operacionalizar tal diferenciação, uma alternativa é a de agregar opções de escolha a algumas características 
do produto, personalizando-o, sem que essas opções afetem o seu custo e o seu tempo de entrega (VIEIRA, 2014). Essa personalização altera a percepção do cliente para uma condição de tratamento especial, definida como Customização em Massa (CM) esta é sugerida quando a empresa objetiva, simultaneamente, eficiência e soluções customizadas. Este conceito é consolidado na manufatura, porém ainda é pouco explorado no setor terciário.

Dentre os métodos existentes para a implantação da CM, apresenta-se o de Tillmann (2008), o qual se desenvolve através de quatro estágios, conforme a Figura 1. No primeiro estágio, busca-se entender o processo macro e seus respectivos problemas. No segundo estágio, o foco recai sobre o entendimento e o potencial atendimento dos requisitos do cliente. No terceiro estágio, a proposta de CM é colocada em prática como teste. No quarto e último estágio é avaliada a efetividade da proposta, a fim de padronizá-la ou, se for o caso, refazê-la.

Figura 1. Etapas para implantação da Customização em Massa. Fonte: Adaptado de Tillmann (2008)

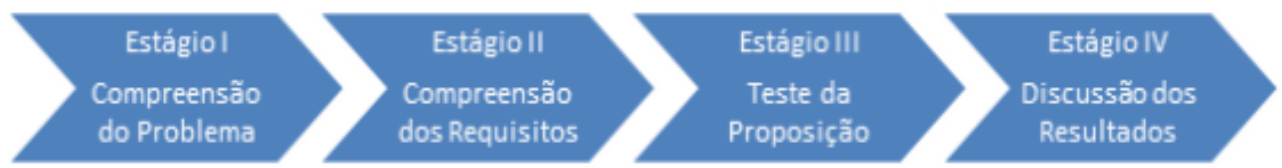

Considerando tanto a estratégia de diferenciação quanto a possibilidade de personalização do pacote de produtos e serviços, foi desenvolvido o presente trabalho associado ao desenvolvimento de um novo negócio de alimentação saudável congelada.

\section{PROCEDIMENTOS METODOLÓGICOS}

O cenário que motivou o presente trabalho está associado ao nicho de mercado de refeições saudáveis, por meio da criação de uma microempresa que pudesse atender às questões de conveniência e de praticidade, representadas no formato de alimentos congelados saudáveis. A sua estruturação está embasada na estratégia de diferenciação e com possibilidade de customização dos serviços prestados.

Por conseguinte, foi desenvolvida pesquisa de natureza aplicada, com o intuito de investigar maneiras para otimizar o posicionamento da empresa frente ao mercado competitivo (GIL, 2010). A abordagem deste trabalho é qualitativa, uma vez que abarca ferramentas que trabalham tanto com a identificação de demandas dos clientes quanto de análise do cenário mercadológico. Os objetivos possuem caráter exploratório, visto que visam proporcionar maior familiaridade com o problema estudado. Por fim, o procedimento técnico adotado é de pesquisa-ação, pois envolve a ação do pesquisador e das partes envolvidas com o problema (GIL, 2010).

Para a operacionalização da CM em microempresas, utilizou-se como base os preceitos de Tillmann (2008). Para tal, foram propostas seis etapas, as quais são apresentadas na Figura 2 e detalhadas a seguir. 
Figura 2. Método proposto. Fonte: Elaborado pelos Autores (2016)

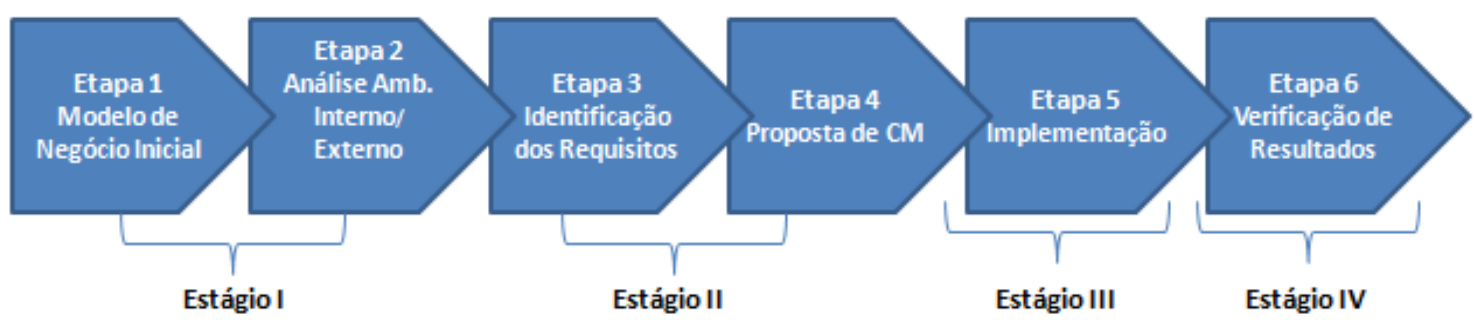

Na primeira etapa, foi realizado o desenho do Modelo de Negócio inicial, a partir de um Modelo Canvas (OSTERWALDER; PIGNEUR, 2011). Na segunda etapa, Análise do Ambiente Interno/Externo, foi desenvolvida uma matriz SWOT, com foco na compreensão dos cenários macro e microeconômico da empresa. Estas duas primeiras etapas foram elaboradas pelos sócios e por dois consultores externos em reuniões semanais durante quatro meses.

$\mathrm{Na}$ terceira etapa, Identificação de Requisitos relevantes para o desenvolvimento tanto do produto quanto do serviço, foi elaborado um brainstorming entre os sócios, os especialistas na área e a nutricionista. Também foram realizadas entrevistas informais com potenciais clientes. Os dados oriundos da etapa três formaram a base da etapa quatro, na qual foi estruturada a Proposta de CM. Simultaneamente, foi desenvolvido o cardápio de maneira a atender aos requisitos previamente levantados. Foram consideradas tanto a viabilidade técnica quanto a econômica de cada opção, até que fosse gerado o cardápio definitivo.

$\mathrm{Na}$ quinta etapa, Implementação, a estratégia de CM foi colocada em prática. Assim sendo, foi definido tanto o layout quanto o planejamento da produção, a partir do cardápio elaborado. Nesta etapa também foram determinadas as estratégias de comunicação e de logística, abrangendo os 4P's do marketing - Produto, Preço, Praça e Promoção (KOTLER; KELLER, 2012). Adicionalmente, foram coletados os primeiros dados de operação do sistema.

$\mathrm{Na}$ sexta e última etapa, Verificação dos Resultados, dentro da lógica do PDCA, foram analisados os dados oriundos da etapa anterior, Implementação. Se os mesmos fossem considerados adequados, o processo seria padronizado; caso fossem considerados inadequados, dever-se-ia rever a proposta. Tanto em uma situação quanto em outra, existe a possibilidade de alteração/pivotamento do Modelo Canvas.

O método proposto ainda se completa com a introdução de um ciclo kaizen (melhoria contínua), o qual deve ser operacionalizado sempre que:

a) Identificada a necessidade de atendimento a novos requisitos;

b) Desejada a ampliação do nível de serviço e/ou;

c) Definida a necessidade de alteração da estratégia vigente.

\section{APLICAÇÃO DO MODELO E RESULTADOS}

Esta seção contém os resultados oriundos da aplicação do modelo descrito anteriormente.

\subsection{Modelo de Negócio Inicial}

O modelo de negócio da empresa está representado no Canvas da Figura 3 e traz a proposta de agregação de valor associada à conveniência e à customização. Esta ação objetiva a potencial fidelização do público-alvo da empresa - representado no Bloco 1 do Canvas do Modelo de Negócio. 
Figura 3. Canvas do Modelo de Negócios. Fonte: Elaborado pelos Autores (2016)

\begin{tabular}{|c|c|c|c|c|}
\hline \multicolumn{5}{|c|}{ Empresa de Alimentação Saudável Congelada - Modelo Canvas } \\
\hline Parceiros-Chave - Bloco 8 & Atividades-Chave - Bloco 7 & Valor - Bloco 2 & Relações - Bloco 4 & Clientes - Bloco 1 \\
\hline \multirow{3}{*}{$\begin{array}{l}\text { Fornecedor de alimentos } \\
\text { Nutricionista } \\
\text { Motoboy } \\
\text { Fornecedor de embalagens } \\
\text { Operadora de cartões }\end{array}$} & $\begin{array}{l}\text { Análise financeira } \\
\text { Preparo do produto e entrega } \\
\text { Marketing, atendimento e venda }\end{array}$ & \multirow[t]{3}{*}{$\begin{array}{c}\text { Saúde } \\
\text { Conveniência } \\
\text { Customização }\end{array}$} & $\begin{array}{l}\text { Redes Sociais } \\
\text { Telefone } \\
\text { E-mail }\end{array}$ & \multirow[t]{3}{*}{$\begin{array}{c}\text { Pessoas que buscam uma } \\
\text { vida saudável, que possuem } \\
\text { pouco tempo livre, que } \\
\text { moram sozinhas e que } \\
\text { pertencem às classes sociais } \\
\text { A, B, C+ }\end{array}$} \\
\hline & Recursos-Chave - Bloco 6 & & Canais - Bloco 3 & \\
\hline & $\begin{array}{l}\text { Insumos de Qualidade } \\
\text { Conhecimento nutricional } \\
\text { Experiência gastronômica } \\
\text { Serviços de logística }\end{array}$ & & $\begin{array}{l}\text { Logística: entrega terceirizada } \\
\text { Marketing: site, SEO e publicidade } \\
\text { online }\end{array}$ & \\
\hline \multicolumn{3}{|c|}{ Custos - Bloco 9} & \multicolumn{2}{|c|}{ Receita - Bloco 5} \\
\hline \multicolumn{2}{|c|}{$\begin{array}{c}\text { Ingredientes, etiquetas e embalagens } \\
\text { Gerais: água, luz, gás, telefone, internet... } \\
\text { Funcionários } \\
\text { Contador e publicidade } \\
\text { Serviço de entrega terceirizado }\end{array}$} & & \multicolumn{2}{|c|}{ Venda direta à pessoa física } \\
\hline
\end{tabular}

\subsection{Análise do Ambiente Interno e Externo}

A Análise do Ambiente foi realizada por meio de uma Matriz SWOT (Figura 4). A matriz reúne as forças e as fraquezas da empresa, bem como as oportunidades e as ameaças do mercado, além da identificação da relação (forte $=9$; média $=3$; fraca $=1$ ) existente entre os itens identificados (MÜLLER, 2003).

Figura 4. Análise SWOT. Fonte: Elaborado pelos Autores (2016)

\begin{tabular}{|c|c|c|c|c|c|c|c|c|c|c|c|}
\hline \multirow{2}{*}{\multicolumn{2}{|c|}{ Análise SWOT }} & \multicolumn{5}{|c|}{ Pontos Fracos } & \multicolumn{5}{|c|}{ Pontos Fortes } \\
\hline & & 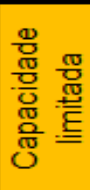 & 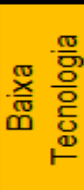 & 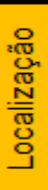 & 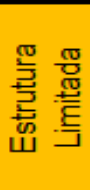 & 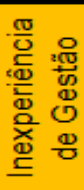 & 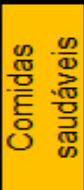 & 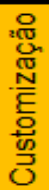 & 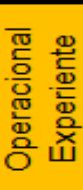 & 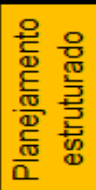 & 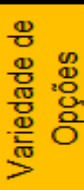 \\
\hline \multirow{5}{*}{ 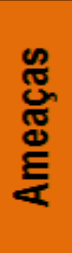 } & Legislação Rígida & 3 & 3 & 1 & 9 & 9 & 3 & 1 & 9 & 9 & 3 \\
\hline & Empresas Tecnológicas & 9 & 9 & 1 & 1 & 3 & 3 & 3 & 3 & 3 & 9 \\
\hline & Flutuação de preços & 3 & 3 & 3 & 1 & 3 & 1 & 9 & 3 & 9 & 9 \\
\hline & Crise Econômica & 9 & 9 & 3 & 9 & 9 & 3 & 1 & 1 & 9 & 3 \\
\hline & Muitos concorrentes & 1 & 3 & 3 & 1 & 9 & 3 & 3 & 3 & 9 & 9 \\
\hline \multirow{5}{*}{$\begin{array}{l}\text { 号 } \\
\text { 옹 } \\
\text { 을 } \\
\text { 흉 } \\
\text { 응 }\end{array}$} & Incentivo microempresas & 9 & 9 & 1 & 9 & 3 & 1 & 1 & 1 & 9 & 3 \\
\hline & Praticidade & 1 & 9 & 3 & 3 & 3 & 3 & 9 & 1 & 3 & 9 \\
\hline & Mercado em expansão & 3 & 3 & 3 & 3 & 9 & 9 & 9 & 3 & 9 & 9 \\
\hline & Redução de desperdícios & 1 & 3 & 1 & 3 & 3 & 3 & 3 & 9 & 3 & 3 \\
\hline & Preços Competitivos & 9 & 9 & 3 & 3 & 9 & 3 & 9 & 3 & 9 & 9 \\
\hline
\end{tabular}

Desta maneira, verifica-se que o quadrante que obteve maior soma dos relacionamentos é o de Desenvolvimento. Ele representa o posicionamento estratégico a ser adotado pelo novo negócio. A estratégia de diferenciação foi selecionada para atender a este posicionamento. A 
partir de uma análise de benchmark, definiu-se uma proposta de valor por meio de um cardápio personalizado, o que ainda não era ofertado pela concorrência.

\subsection{Identificação de Requisitos}

Nesta seção foram identificados os requisitos considerados importantes para o sucesso do negócio do ponto de vista do cliente no processo de tomada de decisão de compra do produto. Foram levantados 20 requisitos, agrupados por afinidade em quatro categorias apresentadas na Figura 5.

Figura 5. Diagrama de Afinidades. Fonte: Elaborado pelos Autores (2016)

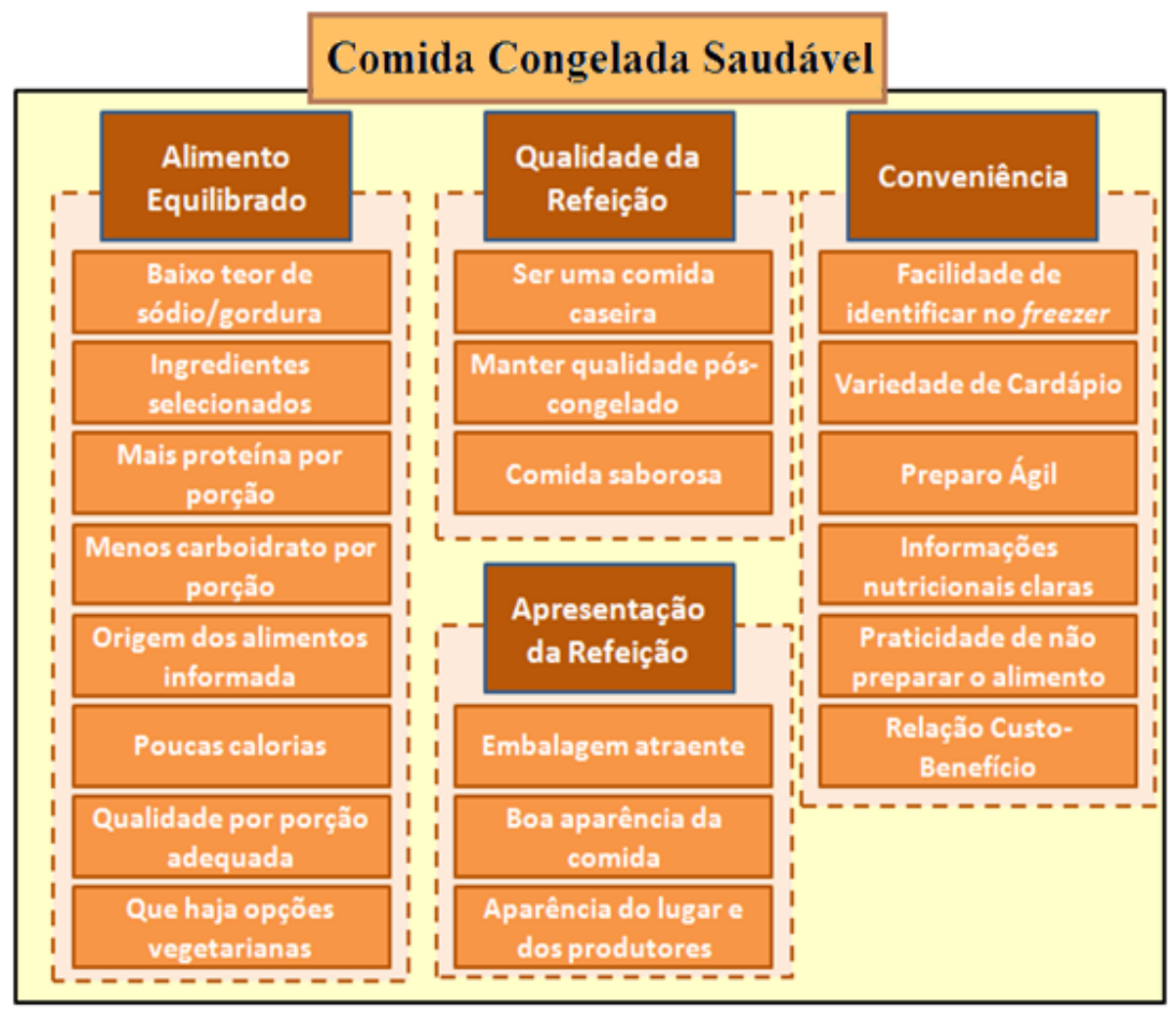

\subsection{Proposta de Customização em Massa}

Inicialmente, por meio de brainstorming entre a nutricionista e os sócios, ocorreu a definição de uma lista com 57 opções de produtos do cardápio. Uma extensa lista refletiria em dificuldades para a gestão de estoques, bem como da linha de produção, em nível de organização. Assim sendo, foi tomada a decisão de enxugar o cardápio, eliminando algumas opções. Resultaram 37 pratos, sendo realizados os cálculos dos custos unitários. Após essa atividade, foram excluídos aqueles considerados com margem inexistente em comparação com os valores praticados no mercado. Finalmente, resultaram 35 opções de pratos que, na lógica de CM, poderiam ser combinados para gerar uma refeição, intitulada 'combo'.

Estes combos foram montados com uma redução no seu preço total quando comparados com a compra individual. A personalização de um combo ocorre por meio da seleção de uma carne e de dois acompanhamentos, configurando uma refeição balanceada e equilibrada em relação ao valor calórico, ao sódio, à gordura e ao glúten. Portanto, o diferencial do negócio recai na possibilidade de personalização do combo por um valor competitivo, especialmente em 
virtude da opção disponível na concorrência apresentar somente pratos previamente definidos.

\subsection{Implementação}

A implementação foi prevista com base nos requisitos identificados no subitem 4.3. A fim de otimizá-la, foi realizada uma análise comparativa considerando o investimento e o arranjo físico necessários. Com isso, projetou-se um espaço pequeno porém bem aproveitado. $\mathrm{O}$ layout foi estruturado considerando o adequado sequenciamento da produção, as exigências da vigilância sanitária, as questões ergonômicas associadas à disposição tanto dos equipamentos quanto dos funcionários, bem como as restrições impostas pela CM.

Uma das principais restrições no estudo foi a necessidade de embalagens independentes para cada alimento do combo. Por exemplo, para um combo de 'surpresa de frango' com 'arroz branco' e 'lentilha', são necessárias três embalagens de tamanhos e peso do conteúdo diferenciados. O fato dos alimentos estarem embalados individualmente é que possibilita as múltiplas possibilidades de comercialização de um combo. Isto demandou mais organização na programação da produção, em virtude de haver mais etapas no processo para um espaço limitado.

Quanto ao estoque, é válido ressaltar que o sistema é empurrado, obedecendo à lógica de ponto de reposição, com estoque mínimo de segurança. Como a rotatividade associada a pequenos estoques é alta, foi possível minimizar as perdas relacionadas ao prazo de validade.

O principal método de comunicação adotado foi por recomendação, via boca a boca, representando cerca de $75 \%$ dos clientes captados (banco de dados dos clientes). Também foram utilizadas redes sociais (Facebook e Instagram) e distribuição de flyers.

Quanto à logística de distribuição, por questões estratégicas de fidelização de clientes e de reforço de imagem, esta foi realizada pessoalmente pelos sócios. Em relação à logística de suprimento, em função do estágio inicial do negócio, os insumos foram adquiridos em pequenos volumes e em mercados locais.

\subsection{Verificação de Resultados}

Nesta seção são apresentados dois tipos de resultados:

a) Alterações no desenho do modelo de negócio;

Dentro da lógica iterativa de um modelo de negócio, a estrutura foi repensada, gerando um novo Canvas para a empresa. A principal mudança está associada ao bloco Clientes, no qual foi incluído um novo perfil, o de pessoas jurídicas, englobando o fornecimento de produtos a cafeterias. Esta mudança no bloco 1 acarretou em alterações nos demais blocos do modelo. A estrutura final do Canvas é apresentada na Figura 6. 
Figura 6. Novo Modelo Canvas de Negócio. Fonte: Elaborado pelos Autores (2016)

\begin{tabular}{|c|c|c|c|c|}
\hline \multicolumn{5}{|c|}{ Empresa de Alimentação Saudável Congelada - Modelo Canvas } \\
\hline Parceiros-Chave - Bloco 8 & Atividades-Chave-Bloco 7 & Valor-Bloco 2 & Relações - Bloco 4 & Clientes - Bloco 1 \\
\hline $\begin{array}{l}\text { Fornecedor de alimentos } \\
\text { Nutricionista } \\
\text { Fornecedor de embalagens } \\
\text { Operadora de cartões } \\
\text { Proprietários de academias }\end{array}$ & \begin{tabular}{|c|} 
Gestão por processos \\
Marketing, atendimento e venda \\
Preparo do produto e entrega \\
Análise financeira \\
Recursos-Chave - Bloco 6 \\
Insumos de Qualidade \\
Conhecimento nutricional \\
Experiência gastronômica \\
Instalações adequadas/org. interna \\
Serviços de logistica
\end{tabular} & $\begin{array}{c}\text { Saúde } \\
\text { Conveniência } \\
\text { Customização } \\
\text { Custo-benefício } \\
\text { Cafeteria (compras } \\
\text { individuais) }\end{array}$ & $\begin{array}{c}\text { Redes Sociais } \\
\text { Telefone } \\
\text { E-mail } \\
\text { Entrevistas abertas (kaizen) } \\
\text { Canais - Bloco } 3 \\
\text { Logística: tele-entrega } \\
\text { Distribuição em academias } \\
\text { Marketing: site, SEO e publicidade } \\
\text { online }\end{array}$ & $\begin{array}{c}\text { Pessoas que buscam uma } \\
\text { vida saudável, que possuem } \\
\text { pouco tempo livre, que } \\
\text { moram sozinhas e que } \\
\text { pertencem às classes sociais } \\
\text { A, B, C+ } \\
\text { Pessoa jurídica: cafeterias }\end{array}$ \\
\hline \multicolumn{3}{|c|}{ Custos - Bloco 9} & \multicolumn{2}{|c|}{ Receita - Bloco 5} \\
\hline \multicolumn{2}{|c|}{$\begin{array}{c}\text { Ingredientes, etiquetas e embalagens } \\
\text { Gerais: água, luz, gás, telefone, internet... } \\
\text { Funcionários } \\
\text { Contador e publicidade } \\
\text { Serviço de entrega próprio }\end{array}$} & & \multicolumn{2}{|c|}{$\begin{array}{l}\text { Venda direta a cliente pessoa física } \\
\text { Venda direta a cliente pessoa jurídica }\end{array}$} \\
\hline
\end{tabular}

b) Resultados da Operação do Negócio.

Considerando o desempenho do negócio durante os seus quatro primeiros meses, percebe-se que há uma tendência de aquisição de pratos individuais a combos (Figura 7). Uma justificativa para este comportamento está relacionada ao acréscimo de novo nicho de mercado pessoa jurídica $(\mathrm{PJ})$ e à oferta de produto ocorrer exclusivamente na modalidade individual, visto que não há margem suficiente para oferta de combo para este perfil de cliente.

Figura 7. Volume de vendas para Pessoa Física (PF) e Pessoa Jurídica (PJ). Fonte: Elaborado pelos Autores (2016)

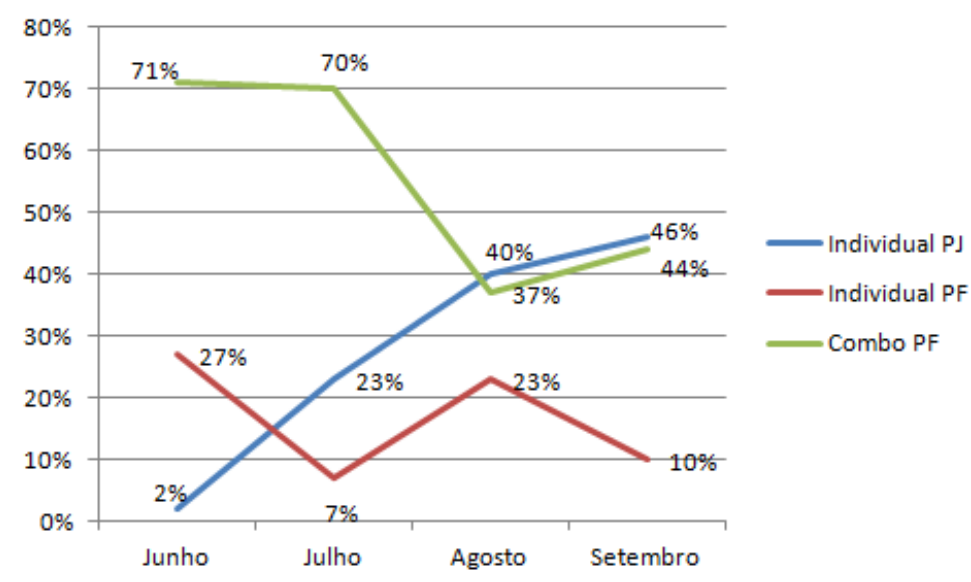

Na Figura 8, é possível visualizar o valor do Ticket Médio - valor médio de compras dos clientes por mês - de PF e de PJ. O comportamento de compra do cliente pessoa jurídica evoluiu com o passar do tempo. O seu Ticket Médio cresceu $279 \%$ nos quatro primeiros meses, sendo que houve um pico de vendas no mês de julho. À medida que as cafeterias começam a desenvolver confiabilidade e a fidelizar, os pedidos se tornam maiores, aumentando seu Ticket Médio. Todavia, há, em quantidade, mais clientes físicos e não 
necessariamente fidelizados, o que refletiu em um menor Ticket Médio.

Figura 8. Ticket Médio. Fonte: Elaborado pelos Autores (2016)

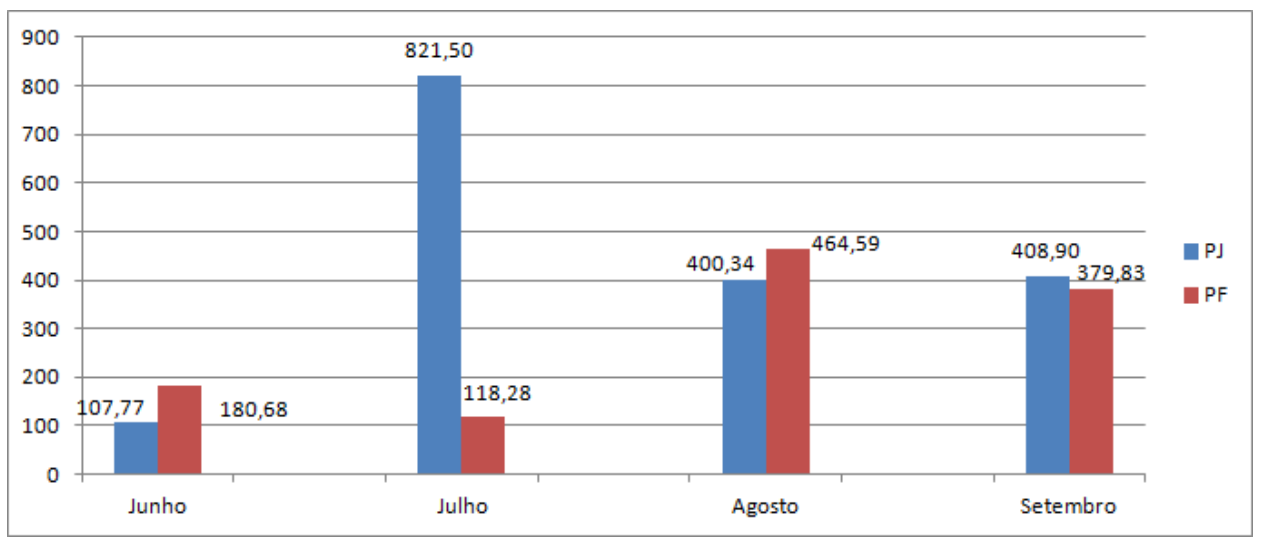

Por fim, através dessa implantação da CM, pode-se atender aos requisitos dos clientes. Além disso, como forma de manter uma proposta única de valor e a satisfação destes clientes, deve ser realizado o fechamento do processo através de uma ação de melhoria contínua (kaizen), dentro do ciclo PDCA. Assim, verifica-se, sempre que necessário, se existem novos requisitos a serem atendidos, novas oportunidades de produtos a serem lançados, ou até mesmo, novas estratégias a serem implementadas. Com isso, objetiva-se a perenização do negócio no mercado.

\section{CONCLUSÕES}

Com a adoção da estratégia de $\mathrm{CM}$, os resultados relacionados aos clientes foram promissores. A liberdade de personalizar o pedido, comprando produtos individualmente, foi aceita pelo mercado, além de captar um novo perfil de cliente, o qual não fora inicialmente planejado: o cliente pessoa jurídica. A inclusão das cafeterias no portfólio de clientes se mostrou viável, uma vez que suas compras são em maior volume e frequência, acelerando, assim, o desenvolvimento do negócio.

Este processo teve início com a identificação de requisitos junto aos clientes. Após análise desses requisitos, os mesmos serviram de base para a tomada de decisão acerca do desenho do negócio. Assim sendo, $85 \%$ dos requisitos identificados foram incorporados aos produtos da empresa, assegurando o alinhamento com as demandas dos clientes.

A implantação da CM deve, também, considerar as peculiaridades de uma microempresa, uma vez que escolhas equivocadas podem impactar criticamente na perenização do negócio. $\mathrm{O}$ conceito de CM, usualmente aplicado em multinacionais, repercute mais significativamente nas pequenas quando comparado às grandes empresas, estas estando mais preparadas para a adaptação necessária à estratégia.

Como sugestão de pesquisa futura, indica-se uma análise relacionada à área de marketing, de maneira a verificar se o impacto na ampliação nos esforços de divulgação repercutem em volume de vendas, em benefícios à imagem, em captação de novos e na fidelização dos atuais clientes. Sugere-se, também, a adaptação de métodos quantitativos para implantação da CM em pequenas e médias empresas (PMEs). 


\section{REFERÊNCIAS}

ALBORNOZ, S. G. Tempo livre e humanização: dúvidas e esperanças ante as novas possibilidades de lazer. Cadernos de Psicologia Social do Trabalho, v13, n.1, p.89-101, 2010.

FITZSIMMONS, J. A.; FITZSIMMONS, M. J. Administração de Serviços: Operações, estratégia e tecnologia de informação. Porto Alegre: AMGH, 2014. 535 p.

FREITAS, A. L. A qualidade em serviços no contexto da competitividade. Revista Produção Online, v5, n.1, 2005.

GIL, A.C. Como elaborar projetos de pesquisa. São Paulo: Atlas, 2010. 200 p.

KOTLER, P.; KELLER, K. L. Administração de marketing. São Paulo: Pearson, 2012. 792 p.

MÜLLER, C. J. Modelo de Gestão Integrando Planejamento Estratégico, Sistemas de Avaliação de Desempenho e Gerenciamento de Processos (MEIO - Modelo de Estratégia, Indicadores e Operações). 2003. 202f. Tese (Doutorado em Engenharia - Ênfase em Gerência da Produção). Universidade Federal do Rio Grande do Sul, Porto Alegre, Brasil, 2003.

OSTERWALDER, A., PIGNEUR, Y. Business Model Generation: Inovação em Modelo de Negócios. Rio de Janeiro: Alta Books, 2011. 300 p.

PORTER, M. E. What is strategy? Cambridge: Harvard Business Review, 1996. 288 p.

RAMOS, A. S. M.; COSTA, F. S. P. H. A. R. Serviços bancários pela Internet: um estudo de caso integrando a visão de competidores e clientes. Revista de Administração Contemporânea, v4, n.3, 2000.

SHARABI, M. Today's quality is tomorrow's reputation (and the following day's business success, Total Quality Management \& Business Excellence). European Society for Organisational Excellence: v25, p.183-197, 2014.

SICHIERI, R. Consumo alimentar no Brasil e o desafio da alimentação saudável. Revista ComCiência, n.145, 2013.

TACHIZAWA, T. et al. Gestão com pessoas: uma abordagem aplicada às estratégias dos negócios. Rio de Janeiro: FGV Editora, 2006. 312 p.

TILLMANN, P. A. Diretrizes para a Adoção da Customização em Massa na Construção Habitacional para Baixa Renda. 2008. 168f. Dissertação (Mestrado em Engenharia). Universidade Federal do Rio Grande do Sul, Porto Alegre, Brasil, 2008.

VIEIRA, J. F. Customização em Massa aplicada ao setor de serviços. 2014. 125f. Dissertação (Mestrado em Engenharia de Produção). Universidade Federal do Rio Grande do Sul, Porto Alegre, Brasil, 2014. 